\title{
Living Together
}

\begin{abstract}
In this chapter, the authors analyze the artifacts in which students explore the idea of living together as a peaceful interaction between people and mutual enrichment of their difference based on basic rights and freedoms as well as mutual respect. In the CLLP, living together is approached as celebration of diversity intertwined with solidarity, equality, and human rights. The analysis reveals that students often approach living together from their own point of view, but are able to see others' perspectives. The chapter discusses how learning about solidarity requires sensitivity for difference and thus lessons on the subject need to be planned carefully to ensure inclusive cultural practices and respect for diversity and difference.
\end{abstract}

Keywords Living together $\cdot$ Solidarity $\cdot$ Equality $\cdot$ Human rights

\section{Defining the Concept of Living Together}

Living together is a theme of multicultural and intercultural education. These concepts have been broadly discussed in scholarly literature with varying emphases and definitions. Some authors prefer to use the term "intercultural," since it captures the interactions between people from different cultures, similarly to "interpersonal" for encounters between

(C) The Author(s) 2022

T. Lähdesmäki et al., Learning Cultural Literacy through

Creative Practices in Schools, https://doi.org/10.1007/978-3-030-89236-4_5 
people and "international" for interaction between nations. In contrast, the term "multicultural" may be perceived as simply referring to the presence of people from different cultural groups (Grant and Portera 2011). These people do not necessarily interact or form a group, but constitute an aggregation or a category. A multicultural school, college, or university, in this particular sense of the term, is an educational setting where the students come from different cultural backgrounds (Spiteri 2017, 5-6).

In 2010, a group of "eminent persons" including European policymakers and scholars commissioned by the Council of Europe's Secretary General Thorbjørn Jagland, prepared a report on the resurgence of intolerance and discrimination in Europe. The report recognizes the confusion about and challenges to the concept of multiculturalism in Europe in the 2000s (see Lähdesmäki et al. 2020, 4-15) and proposes that in response, Europeans should focus on living together (Council of Europe 2010). The authors of the report argued that living together is a concept that enables European societies to combine diversity and freedom and guides them to live in peace, mutual respect, and mutual enrichment based on basic rights and freedoms (Council of Europe 2010, 34). A key to this is interaction and dialogue between members of different ethnic, religious, and cultural groups (Council of Europe 2010, 48).

The report ends with a series of proposals to advance living together in European societies. It identifies educators as the key group of people able to change the way people in Europe think about each other and, thus, enable them to live together better. The report urges "educators and education authorities in all member states to develop intercultural competencies' as a core element of school curricula and to extend these beyond formal education to non-formal settings" (Council of Europe 2010, 61).

\section{The CLLP Approach TO AND DATA ON Living Together}

The first step to learning to live together is celebrating diversity: Respecting and enjoying the variety of lifestyles, cultures, and religions, which includes learning to know one's own culture, appreciating it, and developing cultural identity (DIALLS 2018, 22). In the Cultural Literacy Learning Programme (CLLP), living together was discussed in terms of celebrating diversity, with the intertwined themes of equality, human rights (basic rights and freedoms), and solidarity. The latter theme 
extended the discussion to the idea of empathy and the will to act jointly sharing both advantages and burdens equally and justly (DIALLS 2018, 23).

In the CLLP, the subtheme of the celebrating diversity was explored in five lessons stimulated by three wordless picture books and two short films. The books were Naar de Markt (To the Market 2017) by Noëlle Smit; ZaterDag (Saturday 2018) by Saskia Halfmouw; and Excentric City (2014) by Béatrice Coron. The films were Head Up (2015) by Mentor Gottfried and Anders Artig (Otherwise 2002) by Christina Schindler. These deal with various aspects of diversity, ranging from physical to cultural differences, and explore how to overcome difficulties through teamwork and solidarity. Solidarity was the focus in two lessons based on the film Novembre (November 2015) by Marjolaine Perreten and the book Out of the Blue (2014) by Alison Jay. Equality was the theme of one lesson that used the film Isän poika (Papa's Boy 2010), directed by Leevi Lemmetty to stimulate a discussion of gender roles. Human rights, particularly poverty, were addressed in one lesson stimulated by the film

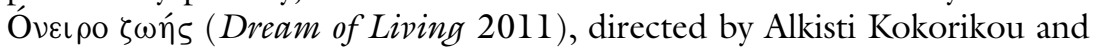
Pinelopi Kokkali.

Our data for this chapter includes 695 individual artifacts from Cyprus (216), Germany (89), Israel (32), Lithuania (65), Portugal (204), Spain (49), and the UK (40). All three age groups explored the subtheme of celebrating diversity. The first two groups explored solidarity, only the second age group explored equality, and only the oldest students explored human rights. However, during the lessons and in the artifacts inspired by the books, films, and classroom discussions, the abovementioned subthemes intertwine.

\section{FoOd AND EvERYdAY ACTIVITIES as Signs of Cultural Diversity}

Three of the lessons-stimulated by the picture books To the Market, Saturday, and Excentric City-were designed to spark discussions on celebrating diversity through accepting and respecting different ways of living. To the Market, aimed at the youngest age group, centers on how food and material goods signal cultural differences. The book narrates a story of a mother and a daughter taking a trip to their local market where a multicultural and multiethnic array of tradespeople sell different foods and goods. The customers at the market look different and are 
interested in different products. At the market, everyday life unites people from different ethnic backgrounds into a harmonious and peaceful whole. The Dutch book ends with a picture depicting the daughter at home next to a table with different foods from the market that recalls still lives in old Flemish paintings. In their artifacts, the children were asked to explore their own cultural identity through material culture: "You have a stall at the market selling products from your country. What do you decide to display and sell?" Instead of a drawing, the children could "work in groups to create a soundtrack for your favorite double spread. What sounds do you hear? What do people say? What languages do you hear? What sounds do animals or objects make?".

Most of the classes drew foods and goods. Their artifacts are images of market stalls with piles of vegetables, fruits, fish, and other products. For instance, a group of Portuguese children drew eight different market stalls with written texts: "Watermelon stall," "Strawberry stall," "Grape stall," "Pork meat," "Fish and fruit stall," "Vegetable stall, carrots and broccoli," "Sea fish stall," and "Sardine stall." The market stalls themselves look inviting with different forms and cheerful colors. Another Portuguese group created a collage of recipes and images of local dishes. The classes from other countries also focused on drawing or making 3D models of market stalls with various items representing the local material culture and traditional dishes. Their locality could be emphasized in the titles of the artifacts. For instance, the Cypriot children titled their artifacts "Traditional products" and include text labels in the images, naming dozens of local dishes and foods.

In the UK, the children also created a soundtrack by playing out an imagined situation in which they were at the market. The voice of a stallholder selling potatoes is at the center of this soundtrack. The teacher reflected on the task by reporting: "They loved the text [To the Market] and we spent a long time exploring each picture. The children worked in small groups to create their own market stall using pictures to create a collage. We then created the sound clip with the hustle and bustle you might hear at a market. They loved it!".

The teacher's comment reflects the enthusiasm with which the children responded to the marketplace as a space of cultural diversity. In the artifacts, the children focused on their own material culture and its local, regional, or national features. The instructions for creating the artifact led most of the children to draw products, not people, or to include only 
market stallholders, not the customers or people interacting in the marketplace. Only a few artifacts include children and explore the marketplace from a child's perspective. In these pictures, the market stalls look huge and the items are placed on such high tables that they are difficult to see from the ground (Fig. 5.1).

The topic of food enables discussions on various cultural issues and social challenges in the classroom, such as: What do we know about the food of other cultures? Why does food represent someone's native culture? Why do children starve in some parts of the world if there is so much food at the marketplace? How can we help people who are starving?

The lesson for the second age group shifted the focus from material goods to activities. The stimulus, the book Saturday, depicts a heterogeneous group of people doing all sorts of weekend activities in an unnamed town. The first double spread depicts a football game or tournament, the second a scene at the market, the third the inside of a grocery store, followed by other settings including a swimming pool, a library, the beach, and a museum. The scenes are depicted from a bird's eye

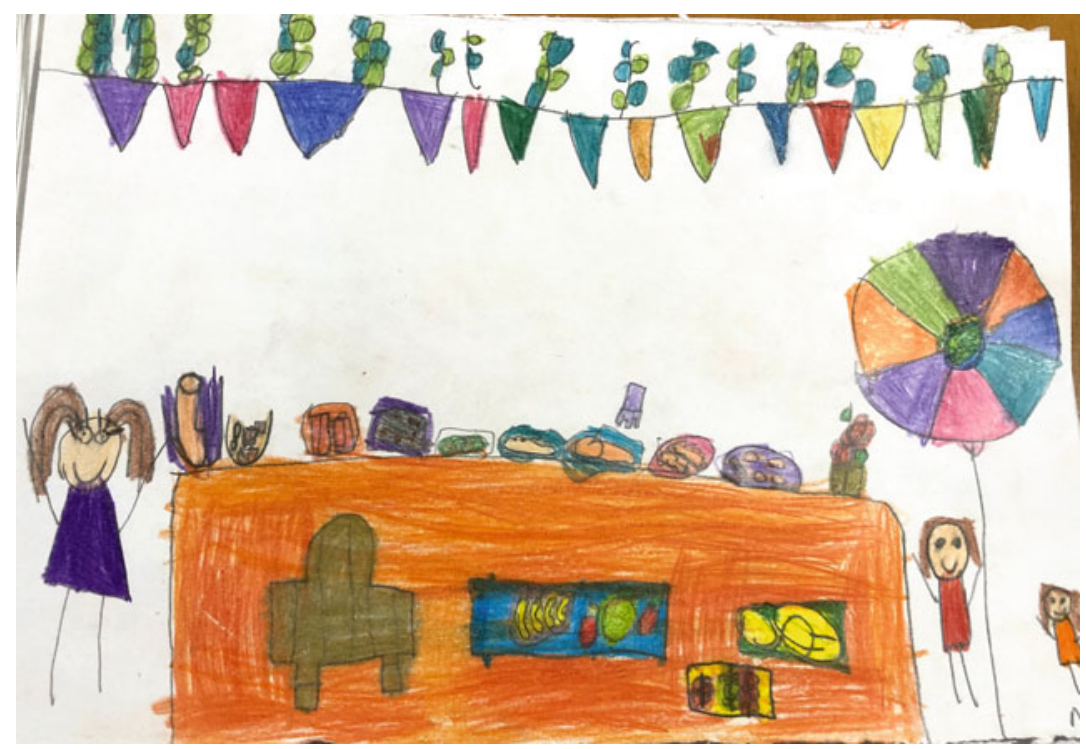

Fig. 5.1 A drawing made by a Cypriot child in the first age group depicting a marketplace with goods from Cyprus 
view. The different ethnicities, age groups, and lifestyles reflected in how people look are thus portrayed from afar. This creates distance between the readers and the protagonists. As Jewitt and Oyama $(2004,147)$ put it in their study of visual meaning: "To see people from a distance is to see them in the way we would normally only see strangers, people whose lives do not touch on ours. We see them in outline, impersonally, as types rather than as individuals."

In this lesson, students were first invited to discuss the following questions: What do you do on a Saturday? Do you have chores to complete? Hobbies? Prayer time for Sabbath? Rest time? Why do you take part in these activities? Next, the students were asked to collaboratively create a scene that would fit into the narrative of the book by depicting what they do on a Saturday. Many of the artifacts are filled with a bustle similar to the one on the pages of Saturday. Only a few artifacts depicted calm scenes.

In general, the artifacts reveal their creators' familiarity with and interest in diverse cultural and social activities. A group of Spanish students, for example, created a drawing with multiple scenes that portrayed visits to the zoo, parties, the theater or cinema, and playgrounds (Fig. 5.2). Their class teacher reported that the task inspired the students:

They really enjoyed talking about what they were doing over the weekend and sharing it with the rest of the class. [...] The students enjoyed the book (which we projected on the screen) and joint conversation. They liked being able to draw and explain it to classmates.

The book, the classroom discussions, the artifacts, and their explanations formed a continuum in which students explored diversity, plurality, and difference through their own everyday activities and interests.

Even though Saturday focuses on one day, it includes a broad temporal span and contextual variety. The scenes in the book represent different seasons and contexts: the streets during summer, a park during autumn, and a town-center skating rink during winter. In their artifacts, students represent several of the locations and activities depicted in the book. The students depict themselves, their friends, and families in the playground, swimming pool, or garden, or at an amusement park. A group of German students explained their artifact in a caption as follows: "We have decided that we will play with friends because we often meet friends on Saturdays. 


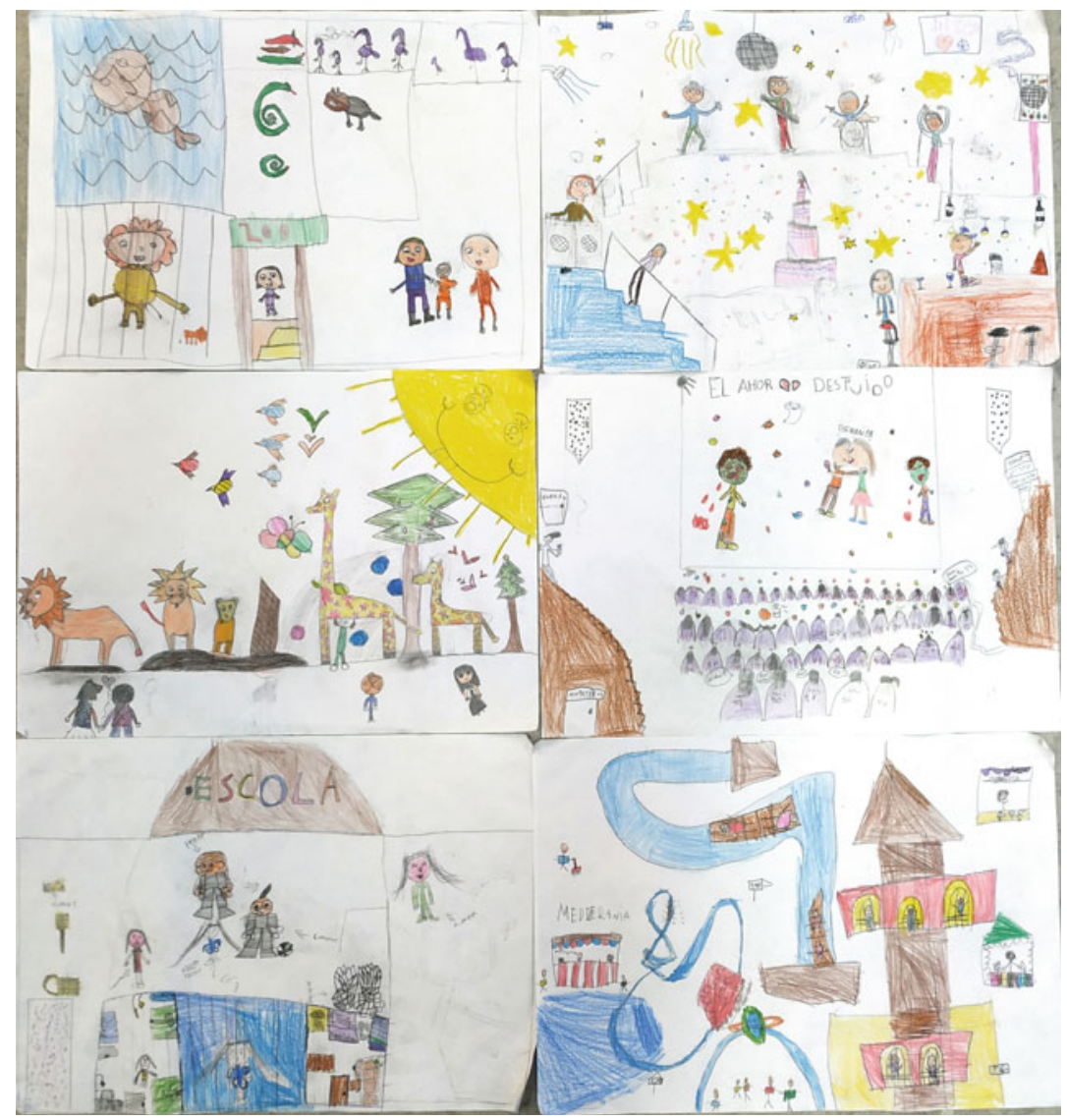

Fig. 5.2 An artifact created by a group of Spanish students in the second age group exploring what they do on a Saturday

Here you can see that we're in the playground." Another German group explained: "Our group drew a swimming pool because we like to go to the swimming pool on Saturdays." A group of Portuguese students wrote: "We chose the pool because we all went there and it is a fun, cool, beautiful activity and a good place to go for a weekend walk with family and friends." Sports were depicted in the artifacts in all countries: Commonly, the children drew scenes in which they are playing football or cycling. 
The oldest students explored living together as celebrating diversity in a lesson based on a leporello (concertina-folded book) entitled Excentric City. The book is made up of elaborate papercuts illustrating a plethora of stories and episodes set in this city. Similar to the two previous lessons, students were asked to create artifacts reflecting their interests in their hometown or city: "Create a leporello with a sequence of sketches representing their own everyday culture."

The students responded to the task in two different ways. The first group of students made artifacts following the instructions to focus on their own everyday life and its episodes, locations, and activities from the point of view of "I." Most of these artifacts illustrate carefree and happy living with one's family and friends. Other students chose to depict struggles that they, their family, or others in general face in their everyday life. For instance, a student from the UK made a papercut depicting a room with a woman dressing followed by images of bombing, graves, and a crying face. In the caption, the student explains:

My story is called "life" because it's about the daily struggles and worries families have in Afghanistan. It starts with a room showing a person waking up. As this person wakes up she puts on her abaya. An abaya is a black dress that is loose. As she goes out she can see a plane overhead. In Afghanistan bombs by the Taliban are usual, whether it be a suicide or an explosive. As the plane goes ahead it drops a bomb on a school and there's a big explosion. This causes much grief and pain for mothers, fathers, and families as they have lost their children, siblings. I have chosen to write about this because it is a daily thing. For some it might be a happy day like weddings etc. But now going out is a struggle. I chose this because it is very dear to me as I have a lot of family members there and they are in constant danger because of the terrorists.

This artifact brings forth the multidimensional reality that many children with a migration history face in their everyday life: Life in Europe is intertwined with life on other continents.

The second group of students explored everyday culture in their artifacts from the point of view of "we." These artifacts emphasize the differences between people and the variety of activities they do in their everyday life. In the captions of these artifacts, the students draw abstract conclusions. In one caption, students from Lithuania stress the idea of difference as the essence of social life: 
We are all different. We painted our celebrations, friends, the gym, school, home - the things which are personally important to us. These drawings indicate our differences because we all think differently, everybody's attitude to the same aspects is different. Everybody is creating a different life and we don't see it as a problem.

Some of the artifacts and their captions reflect even broader openness to difference, which is understood as enriching. Another group of Lithuanian students explains their artifact as follows:

In this book, we wanted to show the world's uniqueness and variety. The world on its own isn't original but people make it such by coloring its parts. Each of us colors a little piece and together the world becomes a rainbow full of creativity and rich in its unique beauty. People's originality was shown in the book. The book shows the brightness of the world. On all of the pages, we can see people. We can make an assumption that the world wouldn't be bright without humans. The world isn't created in colors, we color the Earth with different colors!

This kind of openness to difference can be seen as the premise for an open society in the terms of K. R. Popper (2013). He identified a radical difference between two types of social relations leading either to a closed or an open society. The members of a closed society are united by their ties and belonging to the same group (tribe, nation, family), while the members of an open society overstep the boundaries of these closed groups and use reason to open their minds to the different other, the stranger, the one who is not from their group. This kind of openness is key for living together.

\section{Otherness and Challenges in Teaching Solidarity}

The lesson aimed at the first age group used the film November to stimulate a discussion on solidarity reflects on negotiation between the ideas of open and closed society through the topic of help. In the film, a hedgehog escapes a flood - that threatens its and other animals' habitat-by making a boat from a leaf, like the biblical Noah. On this trip, the hedgehog is accompanied by a snail and a worm-all of them different but sharing the same living environment. This lesson focused on discussing the events in the film: Who helps whom and who needs help. Students were asked to reflect upon occasions when they had helped others. The children 
were asked to create a freeze-frame drama (where they are "frozen" in acting positions like statues) about helping someone. They acted out these frozen positions in pairs and the teachers photographed them. The artifacts and their captions revealed a broad variety of situations where someone needs help and the children are able to respond to the need. The situations ranged from finding help for a peer injured in a game to making friends with a peer who is excluded from others' play, and from covering one's sick father in his bed at night to cuddling a lost puppy on the street.

A lesson for the second age group based on the film Otherwise dealt with solidarity on a more intimate level. In the film, a group of chameleons realizes that one of them is different: This chameleon cannot change its reddish skin color to adapt to the environment and behaves differently from others, acting independently and strangely. The group responds to the difference like the closed society in Popper's (2013) theory, revealing the downside of group egoism - selfish defense of one's own group interest and a tendency to expel difference. When a green chameleon is seized by an eagle, the group decides that the chameleon with a different color is guilty and starts to persecute him. While escaping the persecutors, the chameleon climbs up a mountain and by accident finds the seized green chameleon and rescues it. After this, the rescuer is accepted into the group. The story serves as a challenging starting point to discuss and explore solidarity.

In this lesson, the students were asked to create a drama freeze-frame to show scenes before and after someone is excluded or included. The artifacts and their captions created in that lesson imply that the exercise of first excluding and then including someone emphasized how the students are aware of the narrow social norms for becoming accepted and the difference as a "reason" for exclusion, and they are also able to critically assess exclusive processes. The task thus invited the students to critically explore exclusion and inclusion, or the practice of choosing scapegoats to be excluded from “us" (see Popper's 2013). The exercise did not only provoke the students to recognize differences as reason for discrimination but also to question the logic of discrimination based on difference.

Discussions on difference require sensitivity since pinpointing difference may also deepen the stereotypes that lead to exclusion. It is nevertheless crucial to recognize cultural stereotypes and discriminatory practices in order to prevent exclusion (see Crenshaw 1991) and learn openness, empathy, and a will to understand the other's points of view. 
Therefore, teachers need to make sure that the students do not only recognize existing stereotypes but learn to see how stereotypes are culturally and historically constructed. Only through this can they learn to overcome prejudices related to these stereotypes.

\section{SOLIDARITY WITH NONHUMANS}

Plants and animals are other for human beings as a species. Should people care about all the creatures living on the Earth? Solidarity as the idea of empathy and the will to act jointly, sharing both advantages and burdens equally and justly, can be extended to cover nature and nonhumans (see Chapter 6). In the CLLP, one of the lessons for the second age group sought to explicitly deal with solidarity as understood in this broad view. The lesson was based on the book Out of the Blue, which tells a giant squid that becomes beached upon the shore. Holidaymakers, birds, dolphins, and sharks all work together to return the squid into the sea, demonstrating the interrelated connection between animals, humans, and nature on the coast. In the instructions for artifacts, the students were asked to create a comic strip showing the rescue of a sea creature stranded on the beach. The students were instructed that the comic strips should emphasize solidarity through collaborative-not individual-action and explore how different people have a different part to play in the rescue.

In the artifacts, the students depicted various kinds of sea creatures experiencing trouble. The most popular creatures in the artifacts were different types of whales that were, for instance, "bleeding," "stuck in a plastic," "taken by a storm to the beach," or "trapped in a fisherman's net," as Spanish students explain in their captions. Furthermore, dolphins, swordfishes, jellyfishes, and octopuses were depicted as being stranded or as feeling unwell due to having eaten trash. These images highlight how the students recognize and utilize media images and discussions related to human impact on marine life. After all, the imagery of plastic reefs, stranded whales, and marine animals with their intestines full of plastic is typical media coverage today. A whale full of plastic may even be called a symbol of the pollution of the seas. The stories in the artifacts have, however, a happy ending as other animals and people show solidarity to the sea creatures and rescue them from the trouble. In many of the artifacts, the importance of the sea creatures is emphasized by their huge size compared to people (Fig. 5.3). The size also underlines the huge effort 


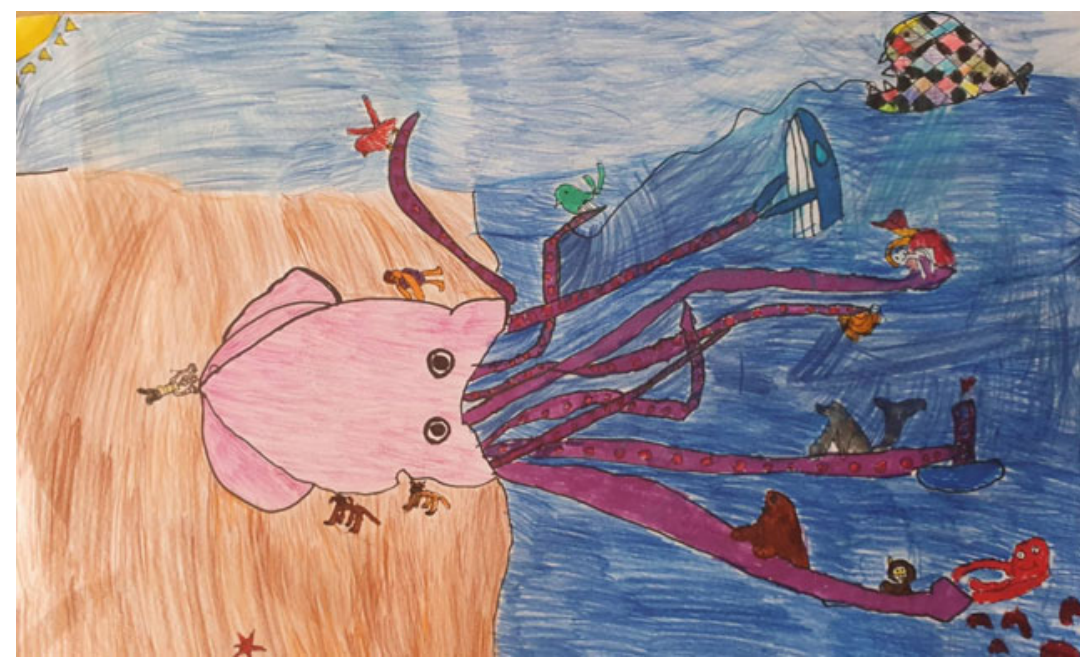

Fig. 5.3 A drawing by a group of children in the first age group from Cyprus explores solidarity through the rescue of a sea creature stranded on the beach

the humans have to take in helping them. This effort seems to be eased by the number of people and other animals helping the sea creatures.

The captions of the artifacts bring forth the understanding of solidarity as empathy for all living creatures and nature and as a will to act jointly with humans and nonhumans to help others. For instance, a group of Portuguese students explained solidarity in the caption as "the pleasure of helping," "particularly important for humanity," and "a form of friendship." The captions also emphasized the power of collaboration: "When we see a problem, we must help because it is better with more hands. Many people helping makes the problem easier to solve," as another group of Portuguese students wrote. In the captions, solidarity as help and respect for others was extended to nonhumans. As another group of Portuguese students noted: "We have to help others and respect everyone. We must always help animals when they are in danger." 


\section{Living Together AND COMPleX CHILD-ADUlt RELATIONSHIPS}

The CLLP included three lessons, one for each age group, in which students explored the relationship between children and adults through different problems. In their lesson, the youngest age group looked at living together and solidarity through the film Head Up, the story of a baby goat who helps an adult goat to jump over an abyss. The baby goat teaches the adult goat, which can be interpreted to be his parent, to look at the sky when he jumps to overcome his fear. The second age group discussed equality using the film Papa's Boy, about a mouse boy who wants to be a ballerina, which also reflects the power relations between a child and a parent. In the film, the father mouse, who used to be a famous boxer, is sad as his son is more interested in ballet than boxing. Yet the boy's dancing skills come in handy when a cat attacks the father: He escapes the clutches of the cat and saves his father. This helps the father appreciate his son's interest in ballet. The oldest students explored human rights by watching the film Dream of Living. The story is about another child-adult relationship: A homeless person's family attempts to encourage him to return home. All three films end with the child and parent living happily together.

The students in each age group created different types of artifacts. To respond to Head Up, the children were given the outline of an adult's hand and asked to draw the outline of their own hand inside it to depict a situation where a child helps an adult. As a response to Papa's Boy, the students were asked to draw a comic strip showing the father's and son's emotions at the beginning, middle, and end of the story. In response to Dream of Living, the students were asked to design crosswords or puzzles with key words from their discussion during the lesson.

The drawings by the youngest children indicate their close relationship with their families: typically, they drew themselves helping either their father or mother, sometimes a sibling. The children depicted various situations where they help their parents with different tasks and depicted themselves as caring for their parents' feelings and emotions. For instance, a Cypriot group of children wrote:

I cut flowers from the garden and I give them to my mum to make her feel happy. I cut flowers from the garden for my mum. I help my dad with his tools and we do crafts. I remind my dad to clean the excavator and 
I help him do it properly. I hug my mum in the dark so that she is not afraid. I cut flowers from the garden for my mum's vase so that our home is cozy and we can be happy. I help my mum to prepare my school bag. I tell her what I want so that she doesn't make any mistakes. I hold my mum's hand when it's raining so that she is not afraid. I hug my mum and dad to make them feel happy. I help my dad clean the truck so that he is happy.

The artifacts illustrate various everyday situations in families very colorfully but also reflect typical gender roles: Children help their fathers repair things, and help their mothers "sweep the floor" and "wash the dishes," as some Portuguese children put it. Besides the film, the children seemed to be inspired by their peers: Cutting flowers for one's mother is repeated by students throughout the Cypriot group. The children's enthusiasm for the idea of being able to help adults was recognized by a Spanish teacher who reported that they "felt very important in explaining to other classmates their experiences about how they help people older than themselves."

After watching Papa's Boy, the children's task was to reconstruct the plot, following its emotional dynamics. Most of the students depicted the emotional turning points: The father's shift from sad to "proud" (as it was commonly expressed in the artifacts or their captions) and the happy ending where both father and son are cheerful and thankful. A group of students from Cyprus describes the emotions at the end of the story with imagined lines: "Bravo son! You can continue ballet and become a famous ballerina," and the son replies: "Thank you, Dad." In such responses, typical to our data, most of the students uncritically explore the characters' emotions and ignore the father's authoritarian pressure on his son. Nevertheless, in each country at least one group of students questions the gendered expectations in the film. In one of the artifacts from Israel, the cat teaches the dad, saying "one has to accept the difference of the different person." Students from different countries wrote captions emphasizing that parents support their children's choices. "Our parents are different from the mouse's father, because our parents believe in our dreams," a group of Portuguese students wrote. These students underline a liberal discourse of "staying true to ourselves" (as stated by a group from Lithuania) reminding that "you can be anything you want and don't let anyone hold you back" (as stated by a group from the UK). The right to individual and equal choices is expressed by a group from Cyprus as follows: 
We can choose whichever dance, sport, or activity we want regardless of a member of our family being a champion in something else. In addition, we can wear the clothes we want because each of us should be ourselves. We can also work in a job we want. Father - a radiologist, mother - a doctor, children - YouTubers or accountants.

The data reveals that already at this age, some children saw their future choices as their right and themselves as independent actors uninfluenced by pressure from social norms or their parents' expectations.

In the lesson stimulated by Dream of Living, the students were asked to explore the theme of living together through abstract concepts inspired by the film. While the artifacts reveal different interpretations, some concepts recurred: Help, company, support, solidarity, and home. The film seemed to raise empathic emotions in students, but they did not explore in the artifacts its core struggle, poverty forcing one to beg, with the concept of human rights-although this was the key subtheme of the lesson.

Instead of making conceptual crosswords, some Lithuanian students reflected on the film through drawings. These artifacts include some explorations of the causes of poverty. One group of students noted how the key in life is to feel happy and not to be alone, but "sometimes people feel unhappy because of their life situations. Sometimes because of using alcohol/drugs, playing in the casino, etc. Sometimes because beloved people leave us alone."

The film inspired another Lithuanian group of students to draw pictures illustrating the challenges of living together. In one of these artifacts (Fig. 5.4), a father is close to his family but at the same time enclosed in a cage. A child, presumably their son, is with his mother, but the father stays apart, alone, and unhappy - emphasized by the grayness of the cage. The father is holding a cigarette and surrounded by bottles, playing cards, and money. The family relations are not further explored in the caption but the students explain the illustrated situation through loneliness:

All humans need warm feelings, attention from others, everyday communication. Everybody needs to come back from work and somebody has to wait for them, listen to stories of what happened during their day, share good and bad feelings. When somebody stays alone, he loses self-trust, becomes depressed, uses alcohol. That is why he needs help from others. 


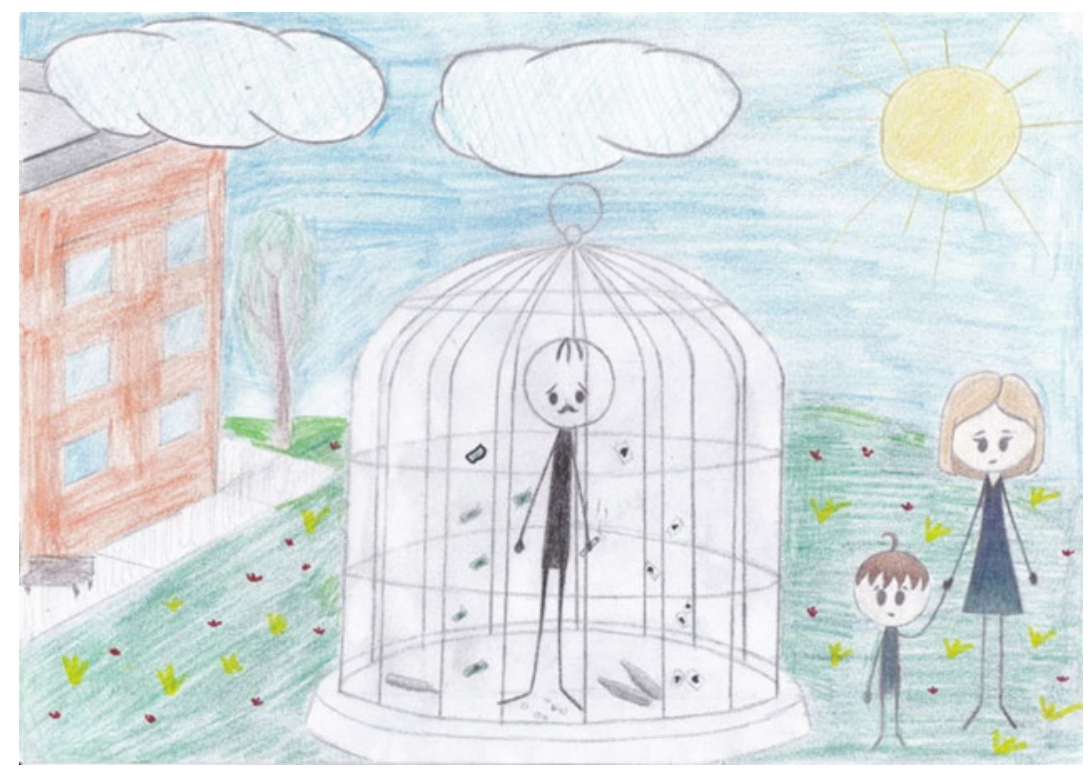

Fig. 5.4 A drawing by a Lithuanian student in the oldest age group exploring the themes of living together and human rights

In the CLLP, all three age groups of students explored the theme of living together through books and films about celebrating diversity, solidarity, equality, and human rights. Their artifacts demonstrated that the students, particularly the older ones, explored different aspects of the themes in an abstract and multifaceted manner, not only from an "I" but also from a "they" perspective. Learning about solidarity requires sensitivity for difference. Lessons on the subject need to be planned carefully to ensure inclusive cultural practices and respect for diversity and difference.

\section{REFERENCES}

Council of Europe. 2010. Living Together: Combining Diversity and Freedom in 21st-Century Europe. Report of the Group of Eminent Persons of the Council of Europe. Paris: Council of Europe. https://rm.coe.int/16806b97c5.

Crenshaw, K. 1991. "Mapping the Margins: Intersectionality, Identity Politics, and Violence Against Women of Color." Stanford Law Review 43 (6): 12411299. https://www.jstor.org/stable/1229039 
DIALLS. 2018. “Cultural Analysis Framework.” https://dialls2020.eu/wp-con tent/uploads/2019/09/resubmitted-cultural-analysis-framework-with-covers heet-.pdf.

Grant, C. A., and A. Portera. 2011. Intercultural and Multicultural Education: Enhancing Global Connectedness. New York: Routledge.

Jewitt, C. and Oyama, R. 2004. "Visual Meaning: A Social Semiotic Approach". In The Handbook of Visual Analysis, edited by T. Van Leeuwen, and C. Jewitt, 134-156. London: Sage.

Lähdesmäki, T., A.-K. Koistinen, and S. C. Ylönen. 2020. Intercultural Dialogue in the European Education Policies: A Conceptual Approach. New York: Palgrave Macmillan.

Popper, K. R. 2013. The Open Society and Its Enemies. Princeton: Princeton University Press.

Spiteri, D. 2017. Multiculturalism, Higher Education and Intercultural Communication Developing Strengths-Based Narratives for Teaching and Learning. New York: Palgrave Macmillan.

Open Access This chapter is licensed under the terms of the Creative Commons Attribution 4.0 International License (http://creativecommons.org/licenses/ by $/ 4.0 /)$, which permits use, sharing, adaptation, distribution and reproduction in any medium or format, as long as you give appropriate credit to the original author(s) and the source, provide a link to the Creative Commons license and indicate if changes were made.

The images or other third party material in this chapter are included in the chapter's Creative Commons license, unless indicated otherwise in a credit line to the material. If material is not included in the chapter's Creative Commons license and your intended use is not permitted by statutory regulation or exceeds the permitted use, you will need to obtain permission directly from the copyright holder.

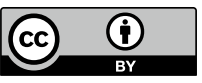

